\title{
抖音短视频中的化学科普现状分析
}

秦晓桥, 卓峻峭 ${ }^{*}$, 王昀之, 杨金金

重庆市南开中学校, 重庆 400030

摘要: 短视频的迅猛发展改变了人们获取信息的方式, 在与化学学科的特点充分融合后, 化学短视频成为化学科普 的重要方式, 化学科普迎来了新时代。本文通过分析抖音短视频中化学科普的现状, 包括化学科普短视频的内容、 形式和影响力等, 为短视频中化学科普的发展提出了若干建议, 以促进化学科普在短视频平台的进一步高质量发展。

关键词: 短视频; 化学; 科普

中图分类号: G64; O6

\section{Current Situation Analysis on Popularization of Chemistry in Tiktok Short Video}

\author{
Xiaoqiao Qin, Junqiao Zhuo *, Yunzhi Wang, Xin Yang \\ Chongqing Nankai Secondary School, Chongqing 400030, China.
}

\begin{abstract}
The rapid development of short video has changed the way people obtain information. After fully integrating with the characteristics of chemistry, short video on chemistry has become an important way for popularization of chemistry, which has ushered in a new era. This paper analyzes the current situation of popularization of chemistry in short video, including tiktok's content, form and influence, and puts forward some suggestions for the development of popularization of chemistry using short videos, so as to promote the further development of popularization of chemistry in the short video platform.
\end{abstract}

Key Words: Short video; Chemistry; Popularization of science

化学是一门与社会生产、生活密切相关的基础中心学科, 为人类的衣食住行带来了许多便利, 现代社会中能源、材料、国防、环保、资源利用、医疗保健等方面的发展都离不开化学 ${ }^{[1]}$ 。近年来, 奶制品污染、白酒塑化剂、盐城响水化工园区爆炸等负面的化学新闻报道, 导致大众对化学产生了 偏见和恐惧, 甚至抹黑化学, 忽视了化学对社会的贡献。造成这些问题的根本原因是大众缺乏基本 的化学常识, 导致对化学的认识是片面的, 甚至是错误的。在此背景下, 向大众普及化学常识, 提 高大众的科学素养, 消除大众对化学的偏见, 是一件意义重大的工作。因此高质量大范围的化学科 普势在必行 ${ }^{[2-5]}$ 。

近年来, 云计算、大数据、互联网和人工智能等现代信息技术深刻改变了人类的生产生活和思 维方式, 同时掀起了知识传播方式的变革, 知识的传播从传统的书本和课堂进入了以短视频为代表 的新型网络媒体中 ${ }^{[6,7]}$ 。分析短视频中化学科普的现状, 可以为化学科普提供新的思路和方法, 促进 化学科普的发展, 为促进知识传递、提升公民科学素养开辟新的路径 ${ }^{[8-11]}$ 。

收稿: 2021-08-13; 录用: 2021-09-10; 网络发表: 2021-09-27

“通讯作者, Email: qq891103@126.com

基金资助: 2019 重庆市普通高中教育教学改革研究课题(2019CQJWGZ3019) 


\section{1 短视频的发展和现状}

短视频是指时长数秒到数分钟的, 以抖音和快手等短视频 $\mathrm{App}$ 应用为载体进行制作、发布的网 络视频。短视频因制作简单, 容易上手, 动态感官刺激强, 逐渐成为人们记录与分享生活的一种潮 流。2021年2月3日发布的《第47次中国互联网络发展状况统计报告》显示, 截至2020年12月, 我国

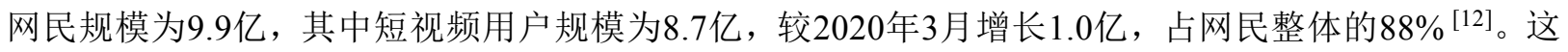
些数据充分表明短视频已经成为中国网民最喜爱的应用之一。

短视频平台具有集图文、动画、影音于一体, 以及时长较短的特点, 有利于大众利用碎片时间 了解化学相关知识。在此背景下, 科学知识与短视频的结合应运而生, 传统的科学知识传播的壁垒 被打破, 科学知识的传播也因与短视频的结合变得生动、高效 ${ }^{[7,13,14]}$ 。化学不仅因为与人们的生活息 息相关而备受关注, 而且化学反应过程特有的视觉冲击在短视频中大放异彩, 这些重要因素均为化 学科普带来了巨大流量。抖音是目前最具影响力的短视频平台之一, 本文对抖音平台上化学科普相 关视频进行了分析。

\section{2 抖音短视频中的化学科普}

根据科普的内容, 可以将抖音短视频平台中的化学科普主要分为化学实验科普、生活化学科普 和化学史科普三大类 ${ }^{[15]}$ 。

\section{1 化学实验科普}

实验是研究化学的重要方式, 也是化学科普的重要途经。相比抽象难懂的化学符号和理论知识, 魔幻多彩的化学实验更能吸引观众的眼球。短视频平台由于具有直观展现影像和声音的特性, 吸引 了一批实验爱好者、化学教育者参与到化学科普实验的创作和传播中 ${ }^{[16]}$ 。根据实验内容不同可将化 学科普实验分为两大类: 趣味性实验和中学化学实验。

\subsection{1 趣味性实验}

趣味性实验是指具有明显的颜色变化、气体的生成、沉淀的生成和其他不符合 “常识” 现象的 化学实验, 这类实验具有独特的趣味性, 即使没有基本化学素养的观众也会被这类实验现象震撼和 吸引 ${ }^{[17]}$ 。抖音平台短视频中经典的趣味性实验主要包括酸碱指示剂变色展示、大象牙膏、水中花园、 碘钟反应、法老之蛇、掌中火、蓝瓶子等, 表 1 中选取了每类实验中较具影响力的 3 个作品进行统计 和研究(表中相关数据统计于 2021 年 8 月 16 日, 后同)。以 “戴博士实验室” 发布的大象牙亳和 “咣当 地球视频” 发布的法老之蛇为例, 这两个视频的点赞量都突破了百万, 说明趣味性实验视频具有很 大的影响力, 主要原因包括震撼的视觉冲击效果和较低的观看知识门槛。大部分趣味性实验视频多 注重实验现象展示, 实验步骤说明和反应原理分析不够充分(表1), 因此属于浅层面的化学科普。即 便如此, 这类奇幻绚丽的实验现象仍向广大观众展示了化学美丽的一面, 一定程度上改变了大众对 化学的偏见。

\subsection{2 中学化学实验}

中学化学实验是教材中经典的, 有一定中学化学知识内涵的化学实验。抖音平台影响力较大的 中学化学实验见表 2 。基于中学教材, 这类视频具有系统性, 易形成比较完整的视频合集, 如 “清华 博士汪的理综课堂” 制作的 “汪博士初高中实验” 合集, 总播放量达到惊人的 1.4 亿次; “佳瑞化学” 发布的 “极简学堂初中实验” 合集, 总播放量也高达5681万次。这类短视频的制作者主要是化学爱 好者和化学教育者, 大部分视频中都有详细的步骤说明和反应原理分析。对视频进行评论的观众以 对化学具有浓厚兴趣的学生为主, 他们在讨论视频实验科学原理的同时期待作者发布更多的实验视 频。这类实验视频为中学化学教学提供了教学资源, 弥补了部分学校化学课堂中实验的缺失, 帮助 学生感受化学实验的魅力。 
大学化学 Univ. Chem. 2021, 36 (10), 2108048 (3 of 6)

表1 短视频中的趣味化学实验

\begin{tabular}{|c|c|c|c|c|c|c|c|}
\hline 实验名称 & 主要内容 & 发布者 & 点赞量 & 转发数 & 时长 & $\begin{array}{c}\text { 有无步骤 } \\
\text { 说明 }\end{array}$ & $\begin{array}{c}\text { 有无原理 } \\
\text { 分析 }\end{array}$ \\
\hline \multirow[t]{3}{*}{ 指示剂 } & 植物指示剂制作及变色现象展示 & 安可托研究所 & 3.7 万 & 6076 & 20秒 & 有 & 无 \\
\hline & 指示剂变色现象展示 & 中科小达人 & 1.5 万 & 991 & 20秒 & 无 & 无 \\
\hline & 指示剂变色现象展示 & 炫酷实验员 & 1745 & 89 & 20秒 & 有 & 无 \\
\hline \multirow[t]{3}{*}{ 大象牙膏 } & 大象牙膏制作及现象展示 & 这不科学呀 & 65万 & 1.3 万 & 25 秒 & 有 & 无 \\
\hline & 大象牙膏实验现象展示 & 戴博士实验室 & 108万 & 6469 & 10 秒 & 无 & 无 \\
\hline & 大象牙膏实验现象展示及分析 & 信口开盒 & 16.8 万 & 192 & 1分26秒 & 无 & 有 \\
\hline \multirow[t]{3}{*}{ 水中花园 } & 水中花园的制作及展示 & 清华博士汪史大爷 & 25.9 万 & 882 & 37秒 & 有 & 无 \\
\hline & 水中花园的制作及展示 & 叔丁基锂 & 1462 & 54 & 12秒 & 有 & 有 \\
\hline & 水中花园的制作及展示 & 飞哥化学 & 3988 & 58 & 20秒 & 有 & 无 \\
\hline \multirow[t]{3}{*}{ 碘钟反应 } & 碘钟实验现象展示 & 猪猪小百科 & 43.2 万 & 1867 & 9秒 & 无 & 无 \\
\hline & 碘钟的制作及说明 & 物理很好玩 & 5.8万 & 374 & 51 秒 & 有 & 有 \\
\hline & 碘钟实验现象展示 & 野兽派实验室 & 9.2 万 & 1380 & 10 秒 & 无 & 无 \\
\hline \multirow[t]{3}{*}{ 法老之蛇 } & 法老之蛇实验过程展示 & 信口开盒 & 113万 & 1304 & 1分19秒 & 无 & 无 \\
\hline & 法老之蛇实验过程展示 & Handykid & 124万 & 2.6 万 & 11秒 & 有 & 无 \\
\hline & 法老之蛇实验过程展示 & 咣当地球视频 & 135万 & 2.4 万 & 1分 5 秒 & 无 & 有 \\
\hline \multirow[t]{3}{*}{ 掌中火 } & 掌中火实验展示 & 鲸探号少儿科学院 & 2435 & 70 & 42秒 & 有 & 有 \\
\hline & 掌中火实验展示 & 实用生活技能君 & 719 & 67 & 15 秒 & 有 & 无 \\
\hline & 掌中火实验展示 & 大播科学实验站 & 356 & 54 & 45 秒 & 有 & 有 \\
\hline \multirow[t]{3}{*}{ 蓝瓶子 } & 蓝瓶子实验展示 & 飞哥化学 & 4.1 万 & 500 & 25 秒 & 有 & 无 \\
\hline & 蓝瓶子实验过程及现象展示 & 冷叔实验室 & 1967 & 146 & 59 秒 & 有 & 无 \\
\hline & 蓝瓶子实验过程及现象展示 & 清华博士汪史大爷 & 1.5 万 & 207 & 37 秒 & 有 & 有 \\
\hline
\end{tabular}

表2 短视频中的中学化学实验内容及影响力分析

\begin{tabular}{|c|c|c|c|c|c|c|c|}
\hline 主要内容 & 发布者 & 点赞量 & 转发数 & 评论 & 时长 & $\begin{array}{c}\text { 有无步骤 } \\
\text { 说明 }\end{array}$ & $\begin{array}{l}\text { 有无原 } \\
\text { 理分析 }\end{array}$ \\
\hline 过氧化氢制氧气并探究性质 & 佳瑞化学 & 40.9 万 & 4222 & 4.3 万 & 21 秒 & 有 & 有 \\
\hline 二氧化碳使燃烧的蜡烛熄灭 & 佳瑞化学 & 110 万 & 9251 & 5万 & 30秒 & 无 & 无 \\
\hline 氯化钠和硝酸银反应 & 北大胡学长 & 8650 & 88 & 327 & 25 秒 & 有 & 有 \\
\hline 高锰酸钾制氯气/氯气与钠反应 & 叔丁基锂 & 932 & 23 & 47 & 15 秒 & 无 & 有 \\
\hline 铜和硝酸银反应 & 叔丁基锂 & 28.8 万 & 622 & 1.9 万 & 14秒 & 有 & 有 \\
\hline 银镜反应 & 清华博士汪的理综课堂 & 28.8 万 & 1.4 万 & 1.8 万 & 27秒 & 有 & 有 \\
\hline 硫酸铜和氨水反应 & 清华博士汪的理综课堂 & 108万 & 8222 & 3.5 万 & 15 秒 & 有 & 有 \\
\hline 硫在空气和氧气中燃烧 & 化学睿哥 & 24.1 万 & 1557 & 3791 & 13秒 & 有 & 有 \\
\hline 铝热反应 & 酒精没有灯 & 708 & 6 & 92 & 10秒 & 无 & 无 \\
\hline 钠的性质探究 & 初中数理化 & 1829 & 531 & 166 & 3分49秒 & 有 & 有 \\
\hline 木炭在氧气中燃烧 & 初中数理化 & 1077 & 307 & 56 & 23秒 & 有 & 有 \\
\hline 测定空气中氧气的含量 & 初中数理化 & 3577 & 468 & 287 & 34秒 & 有 & 无 \\
\hline 焰色反应 & 酒精没有灯 & 1.3 万 & 73 & 506 & 13秒 & 有 & 无 \\
\hline
\end{tabular}




\section{2 生活化学科普}

生活处处皆化学, 生活离不开化学, 化学让生活更美好。生活化学科普短视频内容可分为生活 中的化学常识、生活化学小妙招和生活化学辟谣等三类(表3)。这类视频内容贴近日常生活, 通过简 单易懂的语言分析解决观众遇到的问题和困惑, 因而深受广大观众的喜爱, 点赞量和转发量均很高。 如 “央视财经” 发布的 “食用碱清洗油烟机” , 介绍了用 $50-60{ }^{\circ} \mathrm{C}$ 的温水溶解食用碱配制油烟机清洗 剂, 然后将清洗剂浸润过的纸巾贴在油烟机表面, 就能很好地除去油烟机表面厚厚的油污, 该视频 获得点赞 5.3 万次, 转发 1.2 万次, 影响力非常大。再如 “佩佩的万事屋” 发布的 “辟谣味精致癌” 的 短视频获得点赞 106 万次, 转发 2.8 万次。这类短视频的制作者以生活、美食、新闻媒体为主。视频中 往往会进行简单的化学原理分析, 观众若有一定的化学基础知识, 则可很好地理解视频内容; 即使 观众无化学基础知识, 也能从中学到一些生活技巧和常识。

表3 短视频中的生活化学

\begin{tabular}{|c|c|c|c|c|c|c|}
\hline 类别 & 主要内容 & 发布者 & 点赞量 & 转发数 & 时长 & 有无原理分析 \\
\hline \multirow[t]{3}{*}{ 生活中的化学常识 } & 饮料中的防腐剂: 苯甲酸 & 向波老师 & 156万 & 1.2 万 & 59秒 & 无 \\
\hline & 致命毒气：一氧化二氮(笑气) & 海南禁毒 & 46.6万 & 2.3 万 & 4分58秒 & 无 \\
\hline & $\begin{array}{l}\text { 小苏打、食用碱和泡打粉的区别 } \\
\text { 和用途 }\end{array}$ & 妙招姐 & 2.4 万 & 4998 & 4分2秒 & 有 \\
\hline \multirow[t]{3}{*}{ 生活化学小妙招 } & 乙烯催熟香蕉 & 我是不吃白 & 35.9 万 & 1419 & 1分4秒 & 有 \\
\hline & 食用碱清洗油烟机 & 央视财经 & 5.3 万 & 1.2 万 & 48秒 & 无 \\
\hline & 白醋去除开水壶里的水垢 & 老治测评看得见 & 3.5 万 & 1984 & 40 秒 & 无 \\
\hline \multirow[t]{3}{*}{ 生活化学辟谣 } & 味精致癌？ & 佩佩的万事屋 & 106万 & 2.8 万 & 50 秒 & 有 \\
\hline & 菠菜可以补铁？ & 我是不白吃 & 17.2 万 & 748 & 51 秒 & 有 \\
\hline & 蛋黄发青有毒? & 中国质量新闻网 & 7137 & 362 & 1分 & 有 \\
\hline
\end{tabular}

\section{3 化学史科普}

我国著名化学家付鹰先生曾说过: “化学可以给人知识, 化学史可以给人智慧。” 从烧制陶瓷 和玻璃, 到炼丹和酿酒, 化学伴随着整个人类发展史; 从青铜时代到铁器时代, 再到电气时代, 化 学的每一次发展, 都推动了人类社会的进步。今日头条历史频道官方账号 “头条历史” 推出合集 “门 捷列夫很忙”, 以著名化学家门捷列夫的动画形象为主线进行串联, 详细介绍元素周期表中元素的 相关知识及其背后的故事, 结合有趣的动画和影音, 该视频累计获得了高达 1111 万的播放量。抖音 号为 “简明趣味化学史” 的创作者, 以著名化学家的科研成就为素材, 通过图文结合的形式制作了 短视频, 配上风趣幽默的解说, 让观众体会到化学科研事业对人类发展的重要贡献(表4)。

\section{3 短视频中化学科普的建议}

\section{1 扩大化学科普视频影响力}

表 5 比较了物理科普和化学科普中影响力较大的三个账号的影响力。

表 5 的数据表明, 主要化学科普账号的影响力比主要物理科普账号的影响力要小一些。从抖音账 号主体比较, 化学科普账号主要是化学爱好者和化学教育者个体, 而物理科普账号中有影响力巨大 的“中科院物理所”, 是中国科学院物理研究所的官方账号。

此外, 化学科普账号视频的质量和数量都与物理科普有一定的差距。尽管短视频中化学科普已 有一定的规模和影响力, 但专业的制作者和高质量的作品还远远不够。因此需要更多的个人和机构 积极参与到化学科普短视频的创作中。 
大学 化学 Univ. Chem. 2021, 36(10), 2108048 (5 of 6)

表4 化学名人及其成就

\begin{tabular}{cc}
\hline 化学家 & 主要成就 \\
\hline 波义耳 & 发明了酸碱指示剂; 提出元素说; 得出了波义耳体定律 \\
舍勒 & 实现磷的规模化生产; 发现氧气和氯气; 从尿液中获得尿酸 \\
普里斯特里 & 发现氧气; 发现光合作用; 发明了碳酸饮料 \\
拉瓦锡 & 建立燃烧学说; 开展定量实验; 测定了空气中氧气的含量 \\
卡文迪许 & 发现水由氢和氧两种元素组成; 发现钟乳石的形成原理 \\
戴维 & 发现一氧化二氮; 发明矿工用的安全灯; 得出了定比定律 \\
道尔顿 & 开启化学微观世界; 建立原子论; 推导并证明了倍比定律 \\
马格拉夫 & 分析化学创始人; 首次进行焰色反应; 建立了铁的试验法 \\
沃克兰 & 在鸟粪中发现尿酸; 分析红铅矿发现铬 \\
阿伏伽德罗 & 提出分子论 \\
盖·吕萨克 & 得出盖·吕萨克定律; 研究了钠、钾的化学性质 \\
\hline
\end{tabular}

表5 抖音平台物理科普账号和化学科普账号影响力对比

\begin{tabular}{|c|c|c|c|c|c|}
\hline 类别 & 账号 & 首个作品发布时间 & 作品数 & 点赞总数 & 粉丝数 \\
\hline \multirow[t]{3}{*}{ 物理科普 } & 中科院物理所 & 2018年8月5日 & 128 & 586万 & 184万 \\
\hline & 光头强老师 & 2018年11月22日 & 292 & 3000万 & 305 万 \\
\hline & 物理阿连 & 2019年9月9日 & 347 & 1715 万 & 142 万 \\
\hline \multirow[t]{3}{*}{ 化学科普 } & 戴博士实验室 & 2018年3月4日 & 133 & 458 万 & 80 万 \\
\hline & 清华博士汪史大爷 & 2018年6月7日 & 125 & 414万 & 65 万 \\
\hline & 佳瑞化学 & 2020年11月16日 & 190 & 352万 & 71万 \\
\hline
\end{tabular}

\section{2 提高化学科普内容深度}

化学科普短视频与一般的短视频相比, 更讲究严谨、准确和知识性。观众碎片化的观看习惯虽 然使这种短小精悍的观看方式受到了追捧, 但是受短视频时长限制, 很多化学知识和原理无法充分 展开讲解，观众也许仅仅停留在 “外行看热闹”的层面。

针对这种情况, 制作者在组织素材时, 要充分考虑到观众的化学知识水平, 将化学知识分解, 化整为零，尽量采用通俗易懂的语言进行解决，以达到深层次科普的目的。

\section{3 丰富化学科普视频表述形式}

目前化学科普视频的表述形式主要为视频展示加上文字描述和旁白讲解。这种方式能完整表达 科普内容, 但容易使观众产生灌输感和厌倦感, 进而降低了短视频的完播率, 使科普效果大打折扣。

情景故事是抖音平台科普视频中另一种重要的表述形式, 是指在故事中创设情景, 引入科学知 识。大大增强了视频的趣味性, 深受观众喜爱。“这不科学啊” 抖音号创设了一系列故事情景, 比 如通过对比不同高度的两个蜡烛的熄灭顺序说明火灾时弯腰逃生的科学依据, 再如利用塑料袋制作 能飞10米远的火箭, 等等。凭借这一系列情景故事中的科普, “这不科学啊” 获得 1.4 亿点赞和 1456 万粉丝，成为抖音平台最具影响力的科普号之一。

鉴于此, 化学科普创作者应紧跟短视频潮流, 借鉴其他科普视频中表述形式, 并积极尝试新的 表述形式。

\section{4 结语}

短视频时代, 知识的传播方式发生了革命性的变化, 人们获得知识比以往任何时代都更加便捷 
和廉价。北京大学裴坚老师在《大学化学》 “化学科普” 专刊的序言中提到: “由于云计算、大数 据、互联网和人工智能等现代信息技术的应用, 科普的传播方式正在发生重大的变化, 化学知识的 传播以及化学对社会的影响力不能只在课堂上、考卷上, 更不能只体现在我们的科研成果和论文中, 而应该体现在使更多的民众对化学认同度的提高, 对化学为社会贡献认识的理解 ${ }^{[2]}$ 。” 广大化学工 作者和化学教育者应该把握时代的机遇, 充分发挥短视频的优势, 积极做好化学科普, 传播化学科 学思想, 展示化学科学魅力, 提高公众的化学素养, 让更多人了解化学, 热爱化学, 感恩化学。

\section{参 考 文 献}

[1] 宋心琦. 化学教学, 2015, 37 (2), 3.

[2] 裴坚. 大学化学, 2018, 33 (7), 1.

[3] 汪志慧, 熊辉, 刘芳, 王文云, 胡国志, 龚跃法. 化学教育, 2021, 42 (6), 1.

[4] 刘朋. 科普创作, 2020, No. 1, 80.

[5] 李丽萍, 刘文皓, 奎晓恒. 化学教育, 2021, 42 (1), 76.

[6] 李雪, 曹坚, 肖小明. 化学教育, 2020, 41 (1), 56 .

[7] 郑凌玲, 周爱菊. 化学教育, 2018, $39(20), 52$.

[8] 李厚金, 陈六平. 大学化学, 2020,35 (11), 1 .

[9] 沈剑虹. 出版发行研究, 2020, No. 9, 34 .

[10] 马爱洁, 孙俊立, 杨嫣, 陈卫星, 惠增哲. 化学教育, 2019, 40 (8), 83.

[11] 熊言林, 王晨希. 化学教育, 2015, 36 (19), 73.

[12] 中国互联网络信息中心. CNNIC发布第47次《中国互联网络发展状况统计报告》. [2021-02-03]. http://www.gov.cn/xinwen/2021-02/03/content_5584518.htm

[13] 王艳丽, 钟琦, 张卓, 王福兴. 科技传播, 2020, 11 (上), 1 .

[14] 金心怡, 王国燕. 科普研究, 2021, No. 1, 15.

[15] 田童瑶, 张渘. 大学化学, 2020,35 (11), 9 .

[16] 彭红燕, 张麒麟，尚媛媛. 科技传播, 2020, 12 (上), 116.

[17] 雷以柱, 王倩, 万亚荔, 陈定梅, 卢香宇, 王克良. 化学教学, 2019, 41 (2), 66. 